\title{
The influence of the fire source location on the load-bearing capacity of timber beam exposed to fire
}

\author{
Kamil Kmiecik ${ }^{1, *}$ \\ ${ }^{1}$ Cracow University of Technology, The Faculty of Civil Engineering, 24 Warszawska St., 31-155 \\ Cracow, Poland
}

\begin{abstract}
The fire development in timber buildings may have a different intensity depending on the location in which the fire originated. The largespace timber buildings are characterized by a large area with a comparatively low height, which makes fire-gas evacuation and air circulation difficult. This paper presents an investigation on the influence of the fire source location on the load-bearing capacity of timber beam exposed to fire. The finite element software Fire Dynamics Simulator (FDS) was used for numerical fire modelling, specifying the time-varying spatial maps of the fire-plume-gas temperature on the basis of the equations taken from the fluid dynamics methodology with aerodynamic and thermodynamic variables. The obtained results from the FDS were used to determine the load-bearing capacity of timber beam using the SAFIR software. The results of numerical simulations showed that the fire source location has a significant influence on the load-bearing capacity of timber beam exposed to fire.
\end{abstract}

\section{Introduction}

The estimation and selection of fire scenarios that may occur in buildings are the most essential in fire safety design. Each fire scenario is unique. It's development is influenced by a unique combination of circumstances, factors and events. Fire scenarios are defined as set of conditions that determine the development of fire and the spread of combustion products throughout the building $[1,2]$. The number of fire scenarios for the building is very large. It is impossible to analyze every case of fire. Therefore it is important to choose the most probable fire scenarios, which provides acceptable levels of safety for the building occupants and property.

As mentioned, the fire resistance of timber structures depends on the fire scenario. In large-space timber buildings the fire resistance is estimated by a fully developed fire scenario $[3,4]$. Therefore, the uniformly distributed fire-gas temperature should be considered. In this case the load-bearing capacity of structural elements is relatively low. The advantages of this approach are safe estimation of the fire resistance and simplicity of calculations. The disadvantage of this approach is understatement of the load-bearing

\footnotetext{
* Corresponding author: kamil.kmiecik@pk.edu.pl
} 
capacity of the structure. This may lead to increased costs of fire protection of elements such as beams, columns and girders. Many factors affect whether a flashover occurs. The most important of them are type and location of combustible materials and the access of oxygen [5].

\section{An assumptions of the model}

This paper presents an investigation on influence of the fire source location on the loadbearing capacity of timber beam exposed to fire. The industrial wooden hall was analyzed. The horizontal dimensions of the building were 30,00 x 72,00 meters and height of 5,00 m (Fig. 1). The model includes two open gates with dimensions: $6,00 \times 4,00 \mathrm{~m}$. The loadbearing structure of the building was made of glued laminated timber. Wood properties at fire temperature were adopted in accordance with EN 1995-1-2 [6].

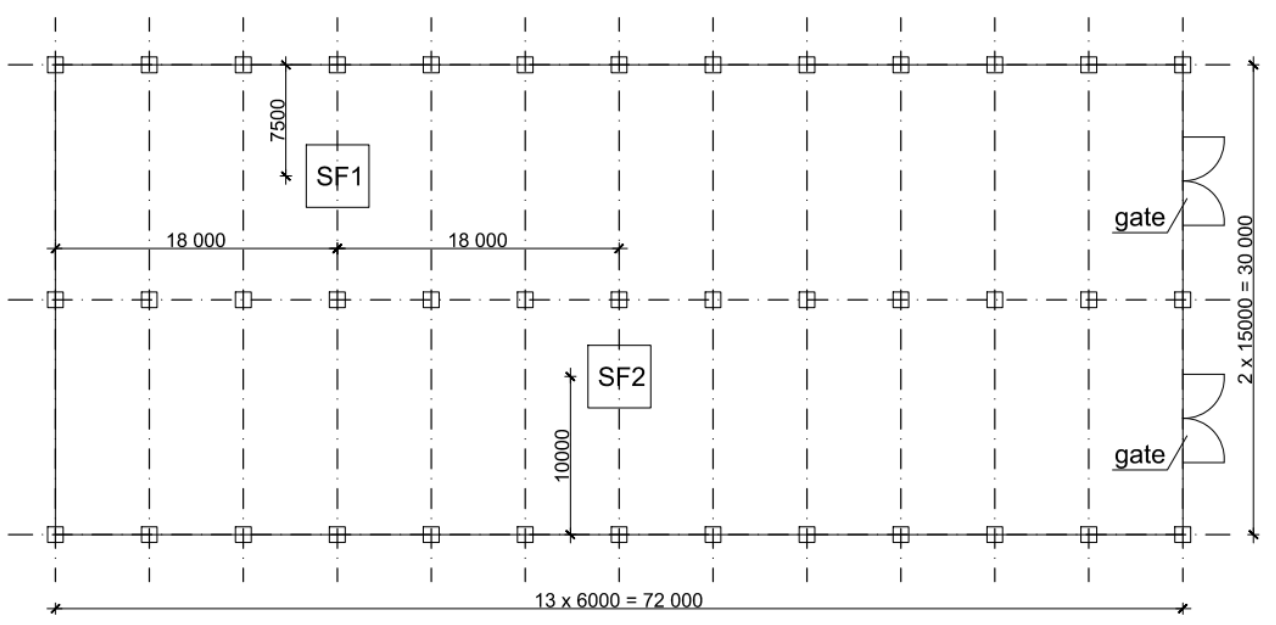

Fig. 1. The floor plan of the building.

Two alternative locations of the fire source were analysed (SF1 and SF2). In both cases a fire power of $20 \mathrm{MW}$ was assumed. Heat release rate was $400 \mathrm{~kW} / \mathrm{m}^{2}$. The subject of the research are the wood-steel-wood timber connections. The geometry of the modeled timber beam is shown in Figure 2. The element is made of glued laminated timber GL 24h class with a density of $420 \mathrm{~kg} / \mathrm{m}^{3}$. The member has the following dimensions of the crosssection: $120 \times 200 \mathrm{~mm}$.

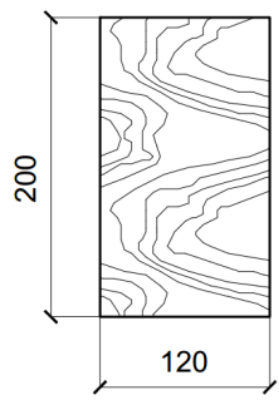

Fig. 2. The cross-section of the timber beam. 


\section{Numerical simulations}

\subsection{Fire development}

Numerical simulations were performed for assumptions from chapter 2. For the fire development modelling, the Fire Dynamics Simulator [7] was used. This software is based on CFD (Computational Fluid Dynamics).

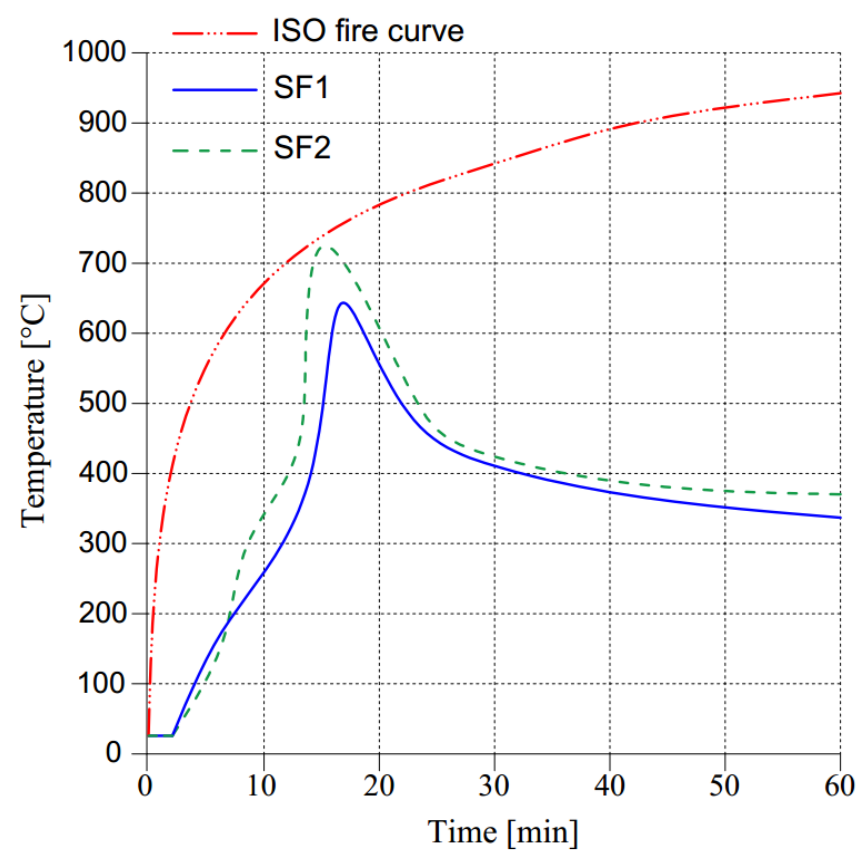

Fig. 3. The standard ISO fire-curve and the plume-gas temperature for SF1 and SF2 during the fire.

The simulation results of the fire development are presented in the Figure 3. The first curve shows the development of the standard fire [8]. After 10 minutes of fire, the temperature reaches about $700{ }^{\circ} \mathrm{C}$. Then the temperature increases and after about one hour it is about $940{ }^{\circ} \mathrm{C}$. It is completely different in the case of other fires. In the SF1 situation, the temperature increases to approx. $700{ }^{\circ} \mathrm{C}$ after 15 minutes of fire. Then the temperature decreases below $400{ }^{\circ} \mathrm{C}$. The case of SF2 is similar to SF1, but the maximum temperature is around $600{ }^{\circ} \mathrm{C}$.

\subsection{Heat transfer through timber beam}

Temperature-time relationship presented in Chapter 3 were used for numerical analysis of heat transfer through the timber beam. SAFIR software [9] was used for simulation. The thermal analysis use models of members with mesh dimensions $2 \times 2 \mathrm{~mm}$. The 4-node quadrilateral elements with one temperature degree of freedom were used to mesh the model.

Figure 4 shows the results of numerical simulations. The temperature distributions of the timber beam after 15, 30, 45 and 60 minutes of standard ISO-fire are shown on Fig. 4a. The isothermal distributions turns into U-shape. The char layer is formed on the outer surfaces of the element. During the fire, the char layer goes deeper into the element $[10,11]$. Figures $4 \mathrm{~b}$ and $4 \mathrm{c}$ present the heat transfer through timber beam after 15, 30, 45 and $60 \mathrm{~min}$ 
of SF1 and SF2 fire exposure respectively. Charring of cross-section is much slower than in the case of ISO-fire. After one hour of fire exposure, almost the entire cross-section has the ambient temperature.

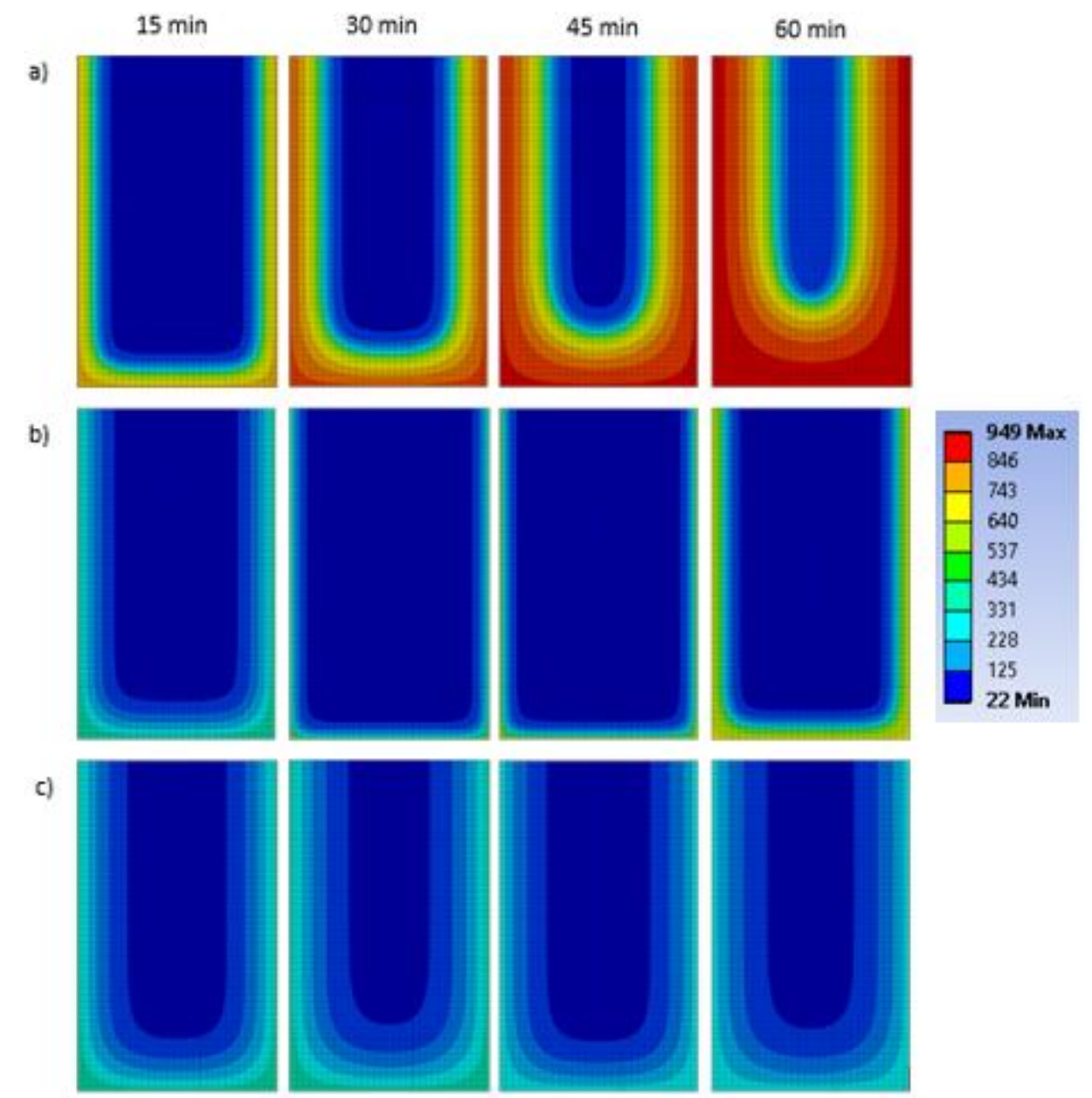

Fig. 4. Temperature distribution of the timber beam exposed to a) standard ISO-fire, b) SF1 fire, c) SF2 fire.

\subsection{Load-bearing capacity}

Load-bearing capacity of a beam in fire conditions depends on the residual cross-section [12]. The char layer is formed at temperature $300{ }^{\circ} \mathrm{C}$. It is assumed that char layer is not able to carry any loads. Therefore, along with the cross-section loss, the stress in the element increases.

In the case of a standard fire, the residual cross-section decreases very quickly. After 30 min it is reduced by $40 \%$ and after an hour by $70 \%$. In S1 and S2 fires, during an hour exposure to a fire, the cross-section was reduced by almost $20 \%$. Residual cross-sections of timber beams exposed to ISO, SF1 and SF2 fires are shown in the Figure 5. 


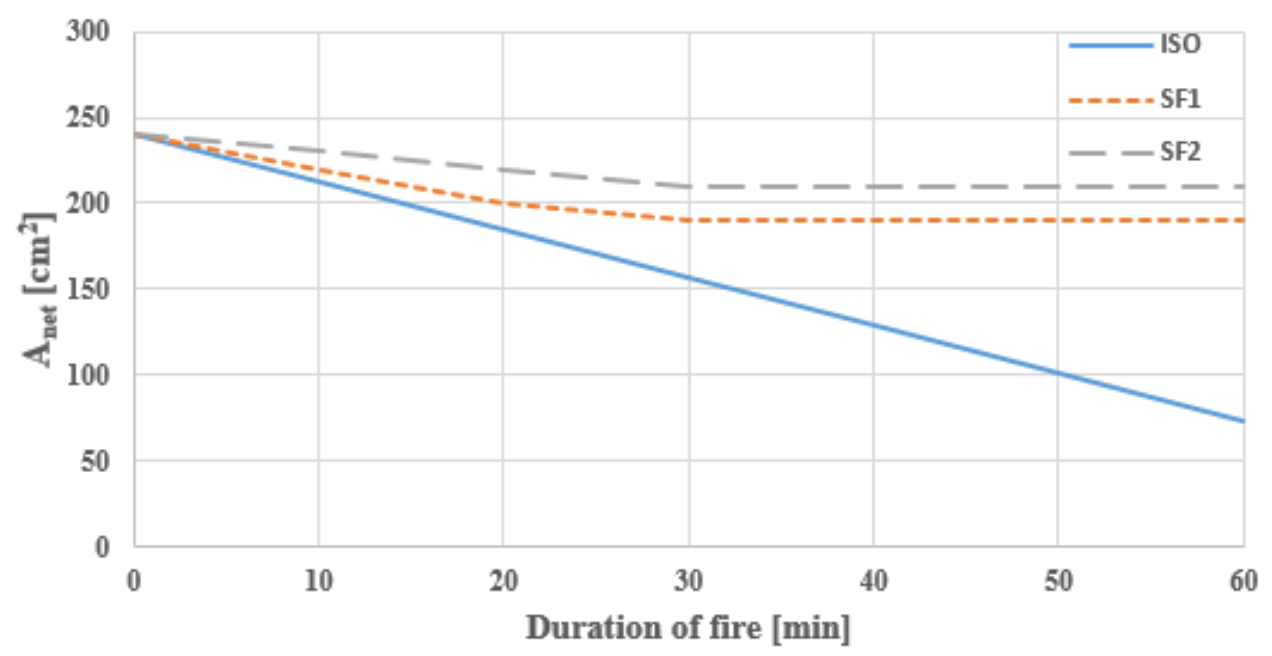

Fig. 5. Residual cross-sections of timber beams exposed to fire.

\section{Conclusions}

In this paper, the analysis of the impact of the fire source location on the load-bearing capacity of the timber beam exposed to fire were carried out. The temperature-time relationship is necessary to determine the heat flow through the element. Numerical simulations of fire development using CFD models can more accurately estimate the spread of a fire. Numerical modelling of the fire, taking into consideration the fire source location is necessary for rational and economical design of timber structures. This may lead to decreased costs of fire protection of elements such as beams, columns and girders.

\section{References}

1. J. Zhang, Q. Xu, Y. Xu, B. Wang, J. Shang, Appl. Phys. Eng. 13, 491 (2012)

2. M. Maślak, M. Pazdanowski, P. Woźniczka, AIP Conference Proceedings, 150007-1150007-9 (2018)

3. J. König, Fire Mater. 30(1), 51 (2006)

4. S. Young, P. Clancy, Fire Mater. 25(3), 83 (2001)

5. K. Friquin, Fire Mater. 35, 303 (2011)

6. EN 1995 1-2 (2004)

7. K. McGrattan, R. McDermott, C. Weinschenk, K. Overholt, S. Hostikka, J. Floyd, Fire dynamics simulator technical reference guide, (NIST Special publication, USA 2013)

8. ISO 834 (1999)

9. J. Franssen, T. Gernay, J Struct Fire Eng. 8, 300 (2017)

10. V.D. Thi, M. Khelifa, M. Oudjene, M. El Ganaoui, Y. Rogaume, Eng. Struct. 143, 11 (2017)

11. D. Lange, L. Boström, J. Schmid, J. Albrektsson, Fire Technol. 51, 1311 (2015)

12. J. Schmid, M. Klippel, A. Just, A. Frange, Fire Safety J. 68, 81 (2014) 